\title{
El mototaxismo en Palmira: ¿solución de transporte y de desempleo o problemática social?
}

\author{
Julio Cesar Montoya R. ${ }^{1}$ \\ Silvio A. Delgado U. ${ }^{2}$ \\ Martha Lucía Fuertes D. ${ }^{3}$
}

\section{RESUMEN}

La presente monografía, cuyo objeto de estudio corresponde al fenómeno del "mototaxismo" en la ciudad de Palmira, plantea la disyuntiva social entre si esta práctica es solo una modalidad de transporte alternativa, o si es una problemática social de connotaciones ilegales. La escogencia de este tópico obedece a la problemática asociada a esta práctica y sus múltiples consecuencias en esta municipalidad.

Por tanto, el presente documento, proyecta una indagación desde diferentes ópticas y en forma secuencial. En efecto, la primera parte concierne al génesis del tópico tratado, es decir, cómo surgió esta práctica en Palmira, en qué barrios se inició, qué servicios prestan, cuánto cobraban inicialmente, etc.

La segunda parte, sitúa el tema en el impacto de esta práctica en Palmira, qué alcance tuvo, cuáles fueron los beneficiados, los afectados, las consecuencias, las reacciones de los grupos de interés, entre otras.

La parte final de la presente investigación, involucra el análisis de casos específicos de las entidades implicadas en el tema, los resultados y discusión de las posiciones de los mototaxistas, de la gente del común, y de las autoridades locales.

Palabras claves: desempleo, transporte ilegal, motocicleta, cultura

\footnotetext{
${ }_{1}^{1}$ Administrador de Empresas, Especialista en Pedagogía para el Desarrollo del Aprendizaje Autónomo, Maestría en Administración de Empresas.Docente de la Universidad Nacional Abierta y a Distancia UNAD. julio.montoya@unad.edu.co

${ }^{2}$ Administrador público, especialista en Educción cultura y política, Magíster en Administración de organizaciones. Docente Universidad Nacional Abierta y a Distancia - UNAD. silvio.delgado@unad.edu.co ${ }^{3}$ Contadora Pública, Especialista en Finanzas, Maestría en Administración, ocente Universidad Nacional Abierta y a Distancia - UNAD. martha.fuertes@unad.edu.co
} 


\section{Introducción}

Desde la aparición de las motocicletas como novedoso medio de transporte en Colombia, por allá en los albores del 70, la forma de desplazamiento terrestre tuvo un giro sorprendente. La gente empezó a sentir curiosidad por manejar este vehículo, y paulatinamente la demanda por estos medios ágiles y económicos de transporte se incrementó a niveles superlativos. A partir de esa época esta clase de automotores se convirtió en el medio de transporte más popular, por su tamaño, versatilidad, funcionalidad y economía.

Ya el mototaxismo como alternativa de transporte público de pasajeros, si se considera una práctica relativamente nueva en Palmira, una modalidad de transporte informal que por haberse proliferado como fuente de negocio, ha traído consecuencias más negativas que positivas en todos los estratos sociales de la municipalidad.

Por tratarse de un tópico de gran incidencia social y mediática para la ciudad de Palmira, la presente investigación monográfica plantea un análisis entre los grupos de interés sobre este fenómeno confluyen variables como empleo, economía, seguridad y delincuencia.

\section{Marco Teórico}

Con base en el propósito de incorporar los conocimientos previos relativos a la presente investigación, se han ordenado en forma lógica los siguientes subtemas, con sus respectivos autores de tal forma que la revisión de estos documentos permite una conceptualización adecuada de los términos relacionados con esta problemática del municipio de Palmira.

\section{El servicio de transporte público en Colombia}

Según Ardila, (2006) el modelo colombiano para la prestación del transporte público colectivo conduce a un transporte de baja calidad, con una flota inflada y una tarifa muy alta, inasequible para los más pobres -quienes más necesitan el servicio-. En este modelo, los municipios otorgan permisos a las empresas de transporte público para operar rutas. Sin embargo, en éste no se obliga a las empresas a ser las propietarias de la flota de buses. Por el contrario, la legislación permite a las empresas "afiliar" buses que son propiedad de pequeños inversionistas, que llamaremos propietarios. Las empresas de transporte público entonces derivan sus ingresos de vender un cupo por cada bus que entra a prestar el servicio y de cobrarle un rodamiento, que no es más que un alquiler mensual por el derecho a operar en las rutas de la empresa. Así, las empresas maximizan la ganancia al inflar la flota por encima del nivel requerido para prestar un servicio adecuado. 
Los propietarios, por su parte, son junto con los conductores los verdaderos encargados de prestar el servicio. No obstante, tienen pocas herramientas a mano, en particular porque no tienen cómo controlar la sobreoferta. En la medida que las empresas han fomentado la entrada de autobuses, el número de pasajeros transportados por cada vehículo ha disminuido. En Bogotá, por ejemplo, entre el año 2001 y el año 2005 el volumen diario de pasajeros transportados por bus bajo $21 \%$ y en las busetas $12 \%$.

Para compensar esta caída, el ordenamiento nacional estipula que la tarifa suba automáticamente en la medida que un bus transporte menos pasajeros. En Bogotá, por ejemplo, entre 1995 y 2005 las tarifas de los buses y busetas de más de seis años subieron un $82 \%$ y $200 \%$ por encima de la inflación. De esta manera los usuarios son los que pagan los platos rotos ya que con la tarifa inflada cubren la ineficiencia de la sobreoferta generada por otros. Por eso, Bogotá y las demás ciudades colombianas tienen uno de los transportes públicos más caros del mundo para el quintil más pobre de la población. Muchos usuarios han dejado de usar el transporte colectivo y han optado por otros modos como caminar o el mototaxismo, que encontró acá un nicho fértil para establecerse. Sin embargo, hay que examinar a continuación por qué miles de compatriotas buscaron sustento en el mototaxismo.

\section{Mototaxismo en Colombia}

Según Brieva Paternina, (2010) del Observatorio Socioeconómico de la Sabana, el mototaxismo como actividad económica se incorporó a la denominada "economía del rebusque, y se ha extendido a todo lo largo y ancho del país y particularmente en las ciudades de la Costa Atlántica, convirtiéndose en una respuesta al creciente desempleo $y$, a su vez, en un problema social.

Para su control las autoridades han implementado una serie de alternativas de regulación 3, como el sistema de pico y placa, y las restricciones al porte de parrilleros o a la circulación a determinadas horas; sin embargo, hasta ahora estas medidas han resultado infructuosas.

\section{El mototaxismo como oferta de transporte Público}

Esta práctica como alternativa de transporte público cuenta con simpatizantes en algún sector de la sociedad, prueba de ello es el artículo que a continuación se referencia:

Raya Bayona, (2010), afirma que los mototaxis son un nuevo transporte público y una solución para hacer frente a los grandes atascos que padecen las ciudades de mayor tamaño. El hecho de que las motocicletas sean un vehículo ligero, rápido y fácil de aparcar, favorece que el usuario pueda recorrer el trayecto en menor tiempo. Además, en algunas ciudades como Madrid, se les permite aparcar en las aceras o disponen de aparcamientos especiales.

Prosigue el autor de este artículo, que también muchas calles cuentan con lagunas para motos en los semáforos, de manera que se colocan delante de los coches 
y pueden salir las primeras cuando el semáforo cambia a verde. Otras ventajas que observa Bayona, frente al taxi tradicional son la menor emisión de gases contaminantes y la posibilidad de conocer la duración y el importe de la carrera con antelación, aunque carecen de maletero y todavía hay pocos vehículos y compañías dedicados a este fin.

\section{Ventajas frente a los medios tradicionales}

Las ventajas más valoradas por los usuarios respecto a los transportes públicos tradicionales son las siguientes:

- $\quad$ Rapidez. Son más rápidas que otros medios y suponen para los usuarios mayor garantía de puntualidad.

- Indicación de la duración del trayecto. Desde el momento en que se hace la reserva, el cliente conoce la duración del trayecto, algo que evita situaciones de estrés y agobios.

- $\quad$ Ahorro de tiempo y de dinero. Los clientes no se preocupan por las condiciones del tráfico y aprovechan mejor su tiempo, al evitar la congestión del tráfico. Disminuye el coste económico que suponen los tan temidos atascos, las obras u otras circunstancias que impiden a un taxi tradicional continuar su marcha normal.

- Conocimiento del coste aproximado en el momento de la reserva. Al no recoger a pasajeros en la calle, siempre tienen que desplazarse desde la base hasta el lugar acordado con el cliente. Por lo general, facturan por el trayecto que realizan desde el punto de recogida hasta el destino final. En el momento de efectuar la reserva, los clientes conocen el importe del viaje, ya que el tiempo de desplazamiento no influye sobre las tarifas.

- $\quad$ Reducción en la emisión de CO2. Con una menor duración de tiempo con el motor en marcha, se disminuye la emisión de gases contaminantes.

- $\quad$ Diferentes modalidades de pago. El pago puede realizarse a través de la página web de la empresa o por teléfono, mediante tarjeta de crédito. Si el cliente lo desea, también puede abonar la carrera al piloto en metálico o con tarjeta después del servicio. En algunas empresas, se pueden adquirir abonos dirigidos a los clientes que requieran el servicio de manera periódica.

\section{Generalidades del mototaxismo en Colombia}

Este tipo de transporte público ha crecido y la reacción de muchos alcaldes ha sido apartar a los mototaxistas de las zonas de ingresos altos. Sin embargo, hay quienes consideran que son parte del desarrollo del país y han sido modelo en otros. 
La ex senadora Cecilia López, directora del Centro de Investigaciones Sociales y Económicas, planteó la fórmula $\mathrm{P}+\mathrm{D}+\mathrm{MSP}=\mathrm{MOTOTAXISMO}$, es decir, pobreza más desempleo, más un mal servicio público es igual a mototaxismo.

Al respecto, la ex senadora explicó al programa UN Análisis de UN Radio: "Esto resume lo que representa este servicio, porque estamos en un país donde la gente pobre de los barrios más marginados, ante la carencia de un sistema de transporte público eficiente, terminó optando por el mototaxismo, que es muy barato, genera empleo y además moviliza a zonas donde no llegan otros vehículos; así que debería ser un servicio reglamentado". (López, 2011)

Las motocicletas, según la Ley 336 de 1996, están catalogadas en el marco de uso particular y por ello no deben considerarse para transporte público. En ese sentido, la actividad del mototaxismo es considerada como ilegal.

El tema genera debate porque Colombia no origina empleo formal suficiente y no cuenta con sistemas de transporte adecuados o eficientes para reducir el uso del automóvil. López precisó: "Ignorar el problema o satanizarlo es políticamente equívoco. Se debe aceptar que es una realidad y es necesario regular este medio de transporte".

En Barrancabermeja se presenta que el $50 \%$ de los transportadores informales ejercen el mototaxismo con motos alquiladas, y esto se ha convertido en un negocio a nivel nacional. Eusebio Peña, presidente de la Cooperativa Asomodesba, de este municipio santandereano, señaló: "Nosotros pedimos una solución al gobierno para que sea permitido un número determinado de estos transportadores que podría ejercer en medios más seguros, como motos de tres llantas, para generar empleo". (Saénz, 2011)

A propósito, el coordinador del Programa de Investigación de Transporte y Movilidad de la Universidad Nacional de Colombia, Néstor Sáenz, mencionó los resultados de un estudio realizado en Barrancabermeja por su grupo de investigación, en el que analizó la percepción de los usuarios del mototaxismo y las razones por las cuales se utiliza este modo de transporte: "Un 31,1\% de los ciudadanos manifiestan su satisfacción porque el servicio es puerta a puerta, el $28 \%$ por el menor tiempo de viaje y el $23 \%$ asegura hacer uso de este porque no hay ruta de transporte público".

En conclusión, los expertos afirman que se requiere una normalización y control de este fenómeno en Colombia, específicamente en algunas zonas que lo requieren para evitar un servicio ilegal de movilización. Asimismo, Sáenz aseguró: "Cuando no hay rutas de servicio público ni planificación, cuando es preocupante el estado de las vías que no permite accesibilidad y excluye a las zonas suburbanas, la gente se ve obligada a recurrir a esta alternativa". 


\section{Análisis de casos específicos, testimonios y estrategias vigentes y futuras}

En esta fase final de la investigación, se recabó información de fuente primaria como los diferentes actores relacionados directamente con el conflicto, en consecuencia, se procedió primeramente a diligenciar un cuestionario a los mototaxistas (40) en total, el $0.01 \%$ de los 4,000 existentes en el municipio.

\section{Tabulación E Interpretación Del Cuestionario}

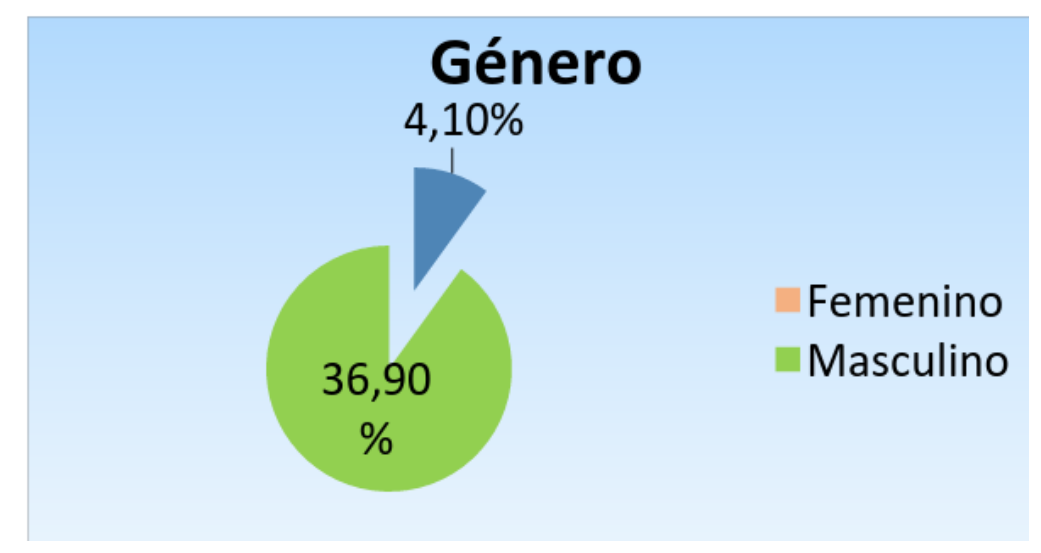

Según los resultados el $90 \%$ de los mototransportadores de Palmira corresponden al género masculino, y un 10\% al género femenino, haciendo la salvedad que dicho porcentaje de mujeres por lo regular obedece a cooperativas o gremios formalizados de este tipo de transporte.

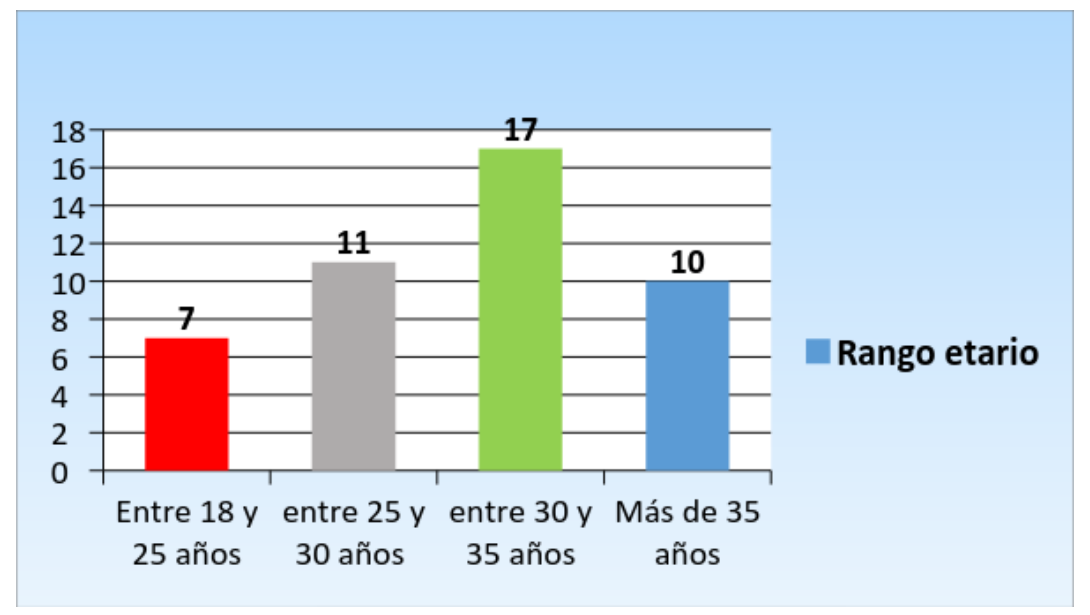

El rango de edad más común entre los mototransportadores está ubicado entre 30 y 35 años, (42.5\%) edad que infiere que son personas que sigan siendo jóvenes pero que para la realidad laboral, se encuentran pasados de edad. 


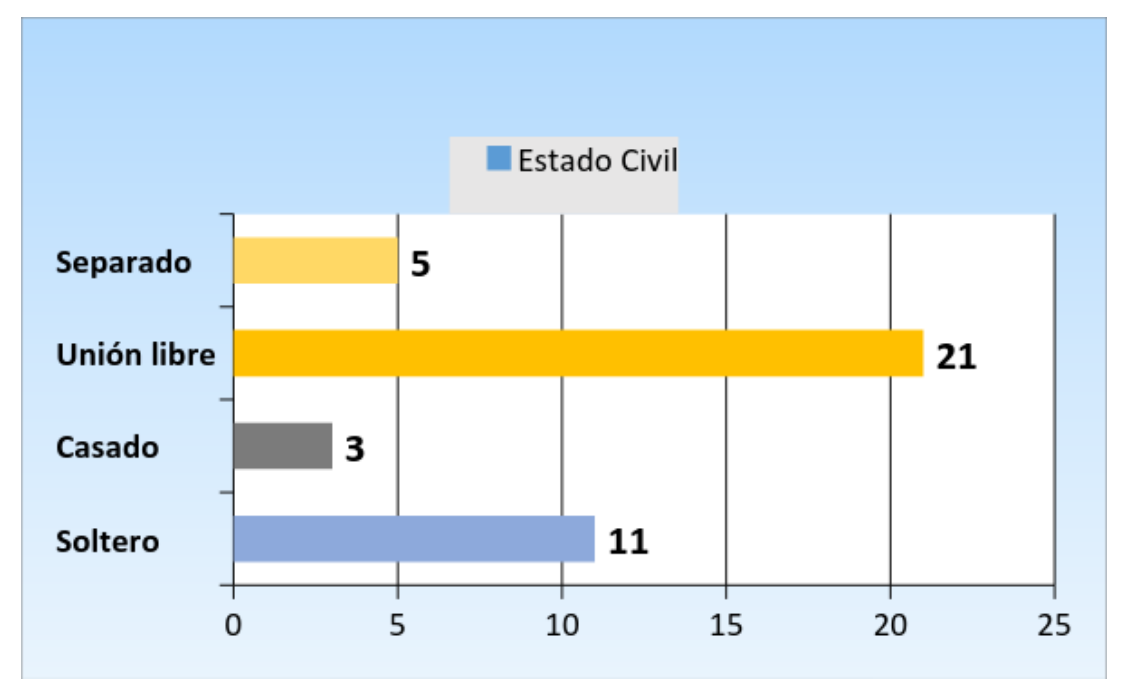

Un poco más del $50 \%$ de los encuestados afirman vivir en unión libre, una modalidad civil muy arraigada no solo en Palmira, sino en todo Colombiana. Llama la atención, que el $45.83 \%$ corresponde a personas solteras, lo que de alguna potencializa la posibilidad de situaciones de acoso sexual, o de propuestas amorosas entre el moto-transportador y el usuario (pasajera).
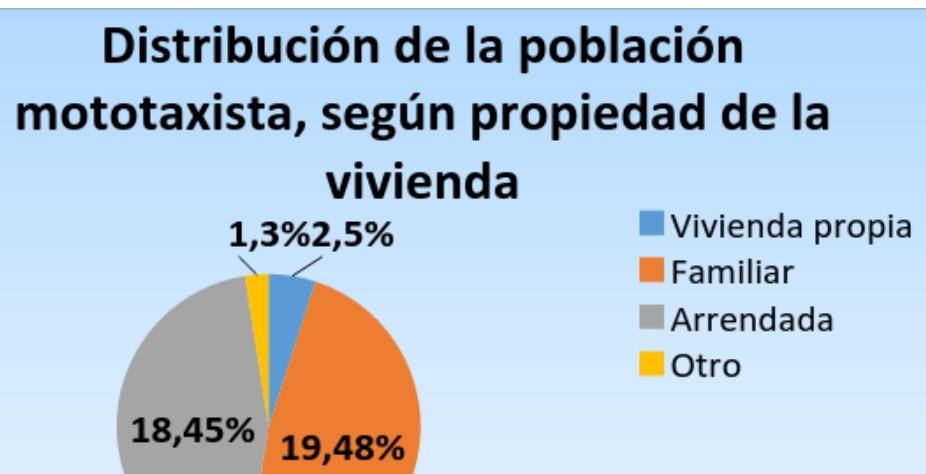

Con base estos resultados, los mototaxistas o viven aun con sus padres 0 familiares, o viven en casas arrendadas, (47\% y $45 \%$ ), respectivamente, lo que es razonable teniendo en cuenta sus antecedentes de desempleo y falta de ingresos económicos estables. 


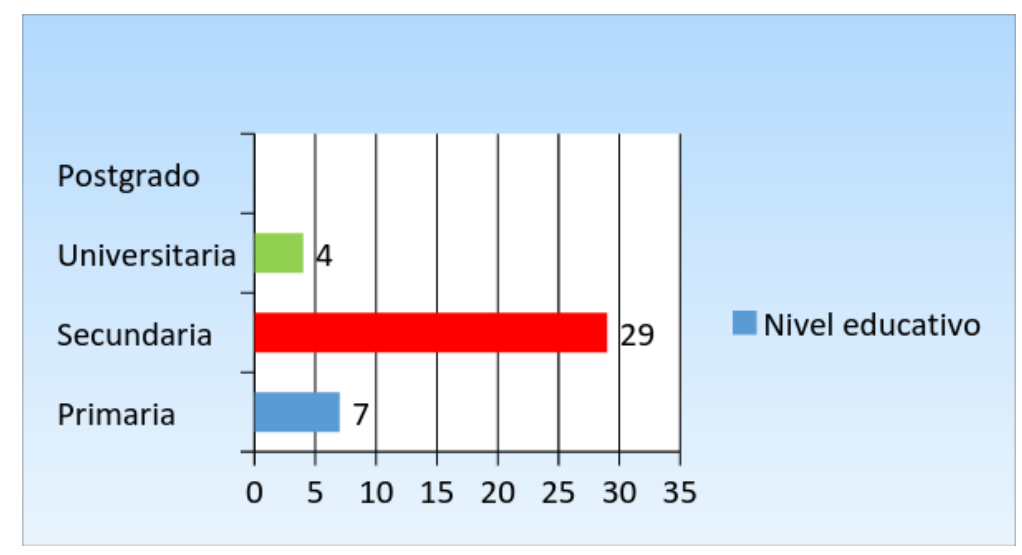

29 personas $(72.5 \%)$ de los mototaxistas encuestas, manifiestan ser bachilleres, hecho que es lógico en esta época, donde la gente al menos logra obtener su grado de secundaria. Destacable que haya un $10 \%$ de personas que dicen haber cursado estudios universitarios, contingencia que tampoco sorprende por la escasez de oferta laboral para los profesionales.

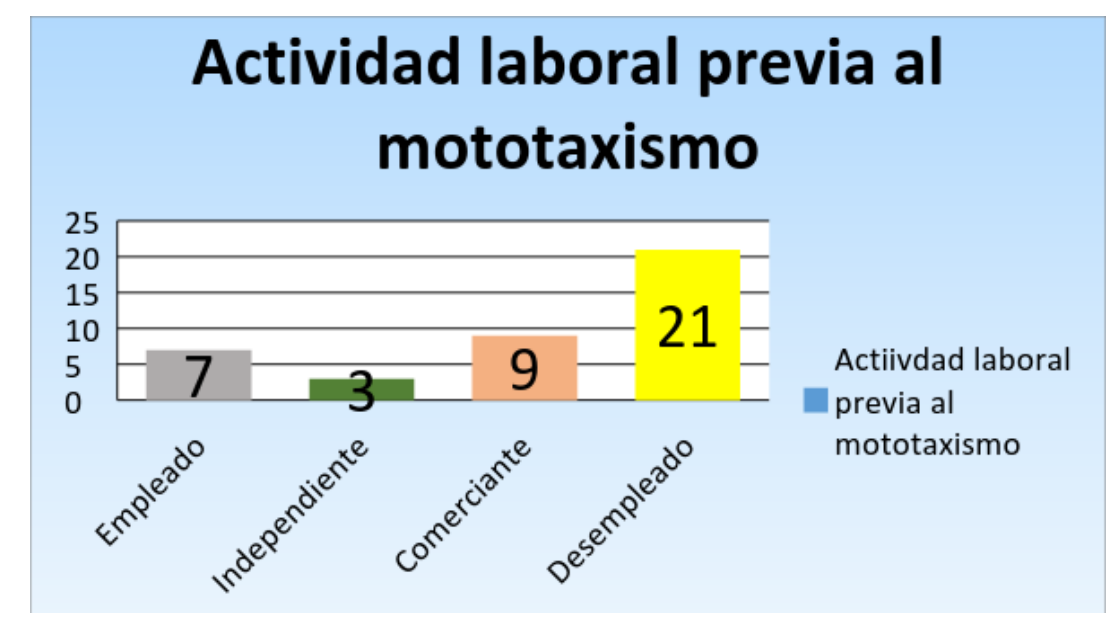

Ligeramente superior a la media de entrevistados 52.5 son desempleados, situación que muy probablemente sea la causa del porque se han ubicado a llevar a cabo estas labores de transporte público.

\section{Distribución de la población mototaxista, según propiedad de la motocicleta}

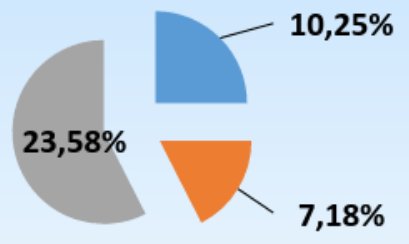
Vehiculo propio
Prestado
Rentado


Un $58 \%$ de los encuestados sostienen que las motocicletas que operan no son propias, dicha situación deja entrever que detrás de esta práctica existen grupos económicos o personas con poder económico detrás de este negocio. Incluso el $25 \%$ de los encuestados afirma que el vehículo es propio, pero que aún lo están pagando.

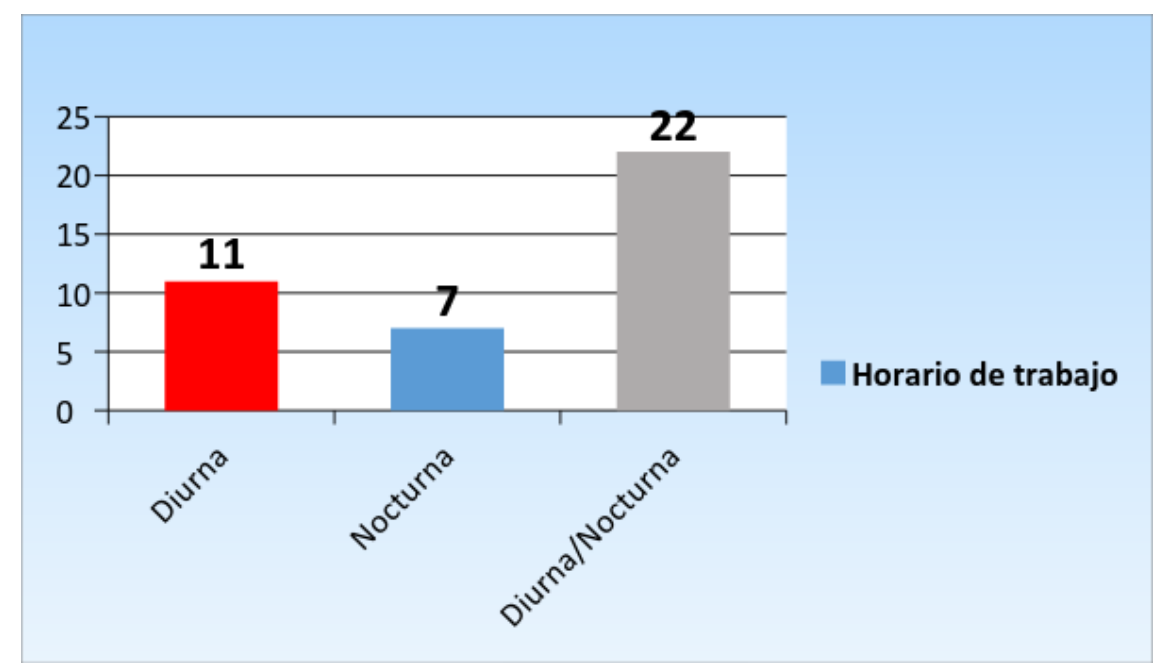

En cuanto a la jornada, un poco más del $50 \%$ de los entrevistados labora dia y noche, lo que infiere dos cosas; o que el mototransportador está muy necesitado o que el negocio es muy rentable.

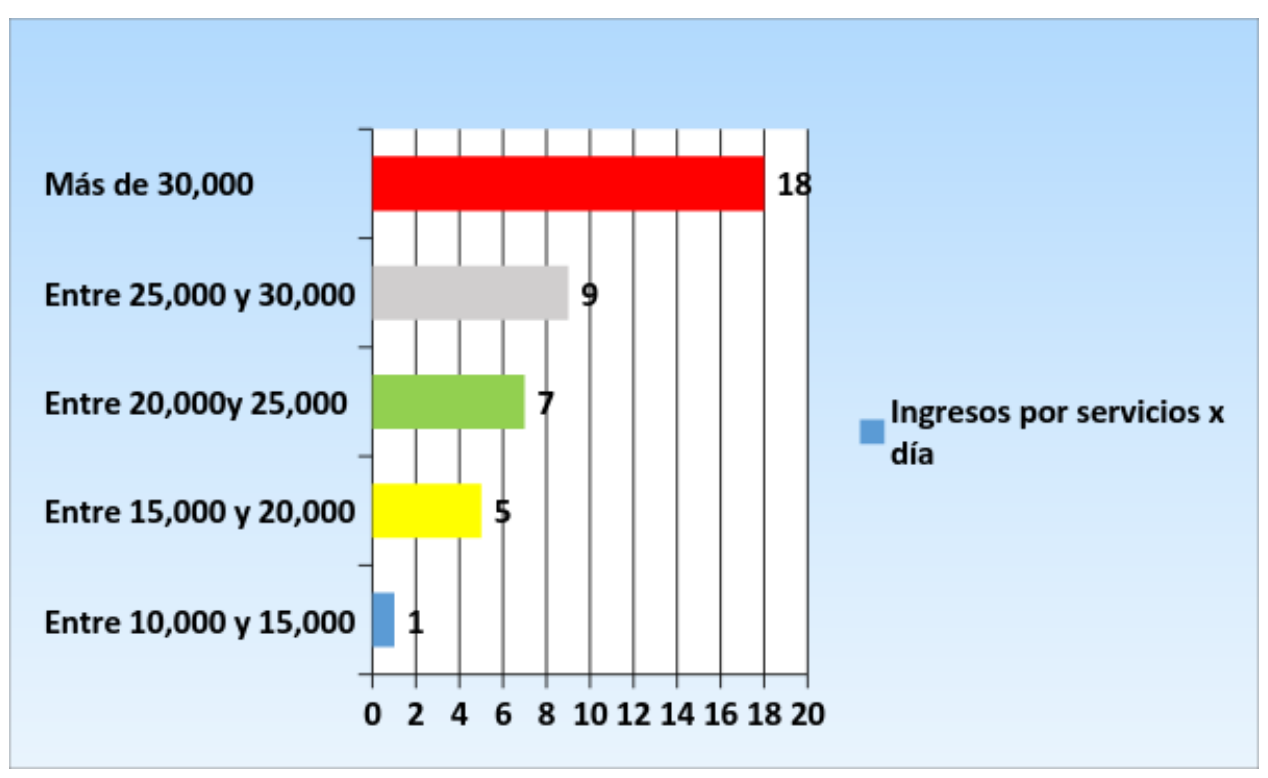

El $45 \%$ de los mototaxistas afirma ganarse más de 30,000 al día, lo que en este contexto se considera un salario módico, pero suficiente, algunos ganan más obviamente. 


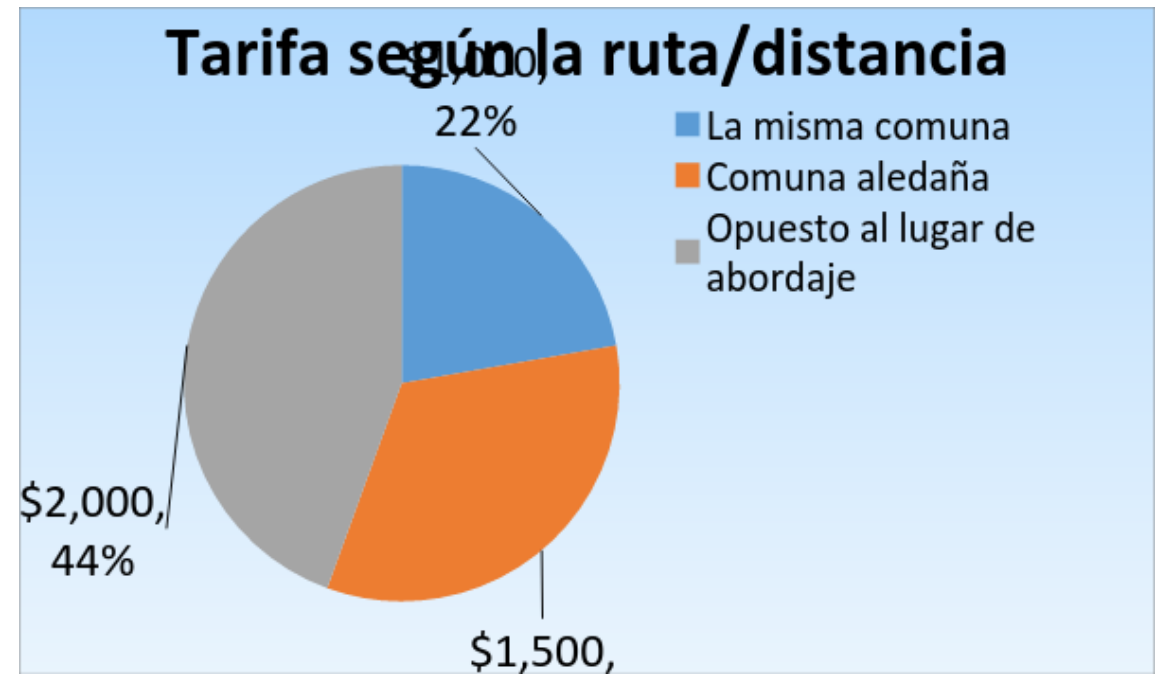

En cuanto a las tarifas los precios son directamente proporcionales a la distancia del destino.

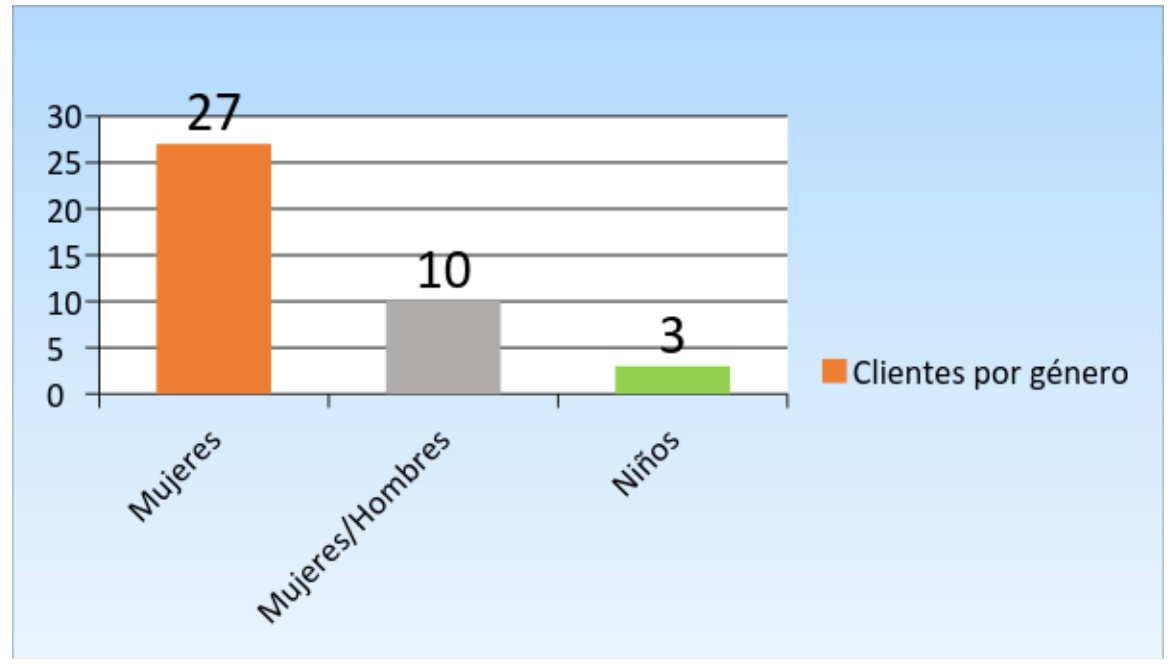

El $67.5 \%$ o sea 27 personas, afirman que transportan solo mujeres, pero un $25 \%$ (10 mototaxistas) sostienen que transportan de ambos géneros, esto da a significar o que algunos mototaxistas son más arriesgados o tienen mayores necesidades de ingresos. 


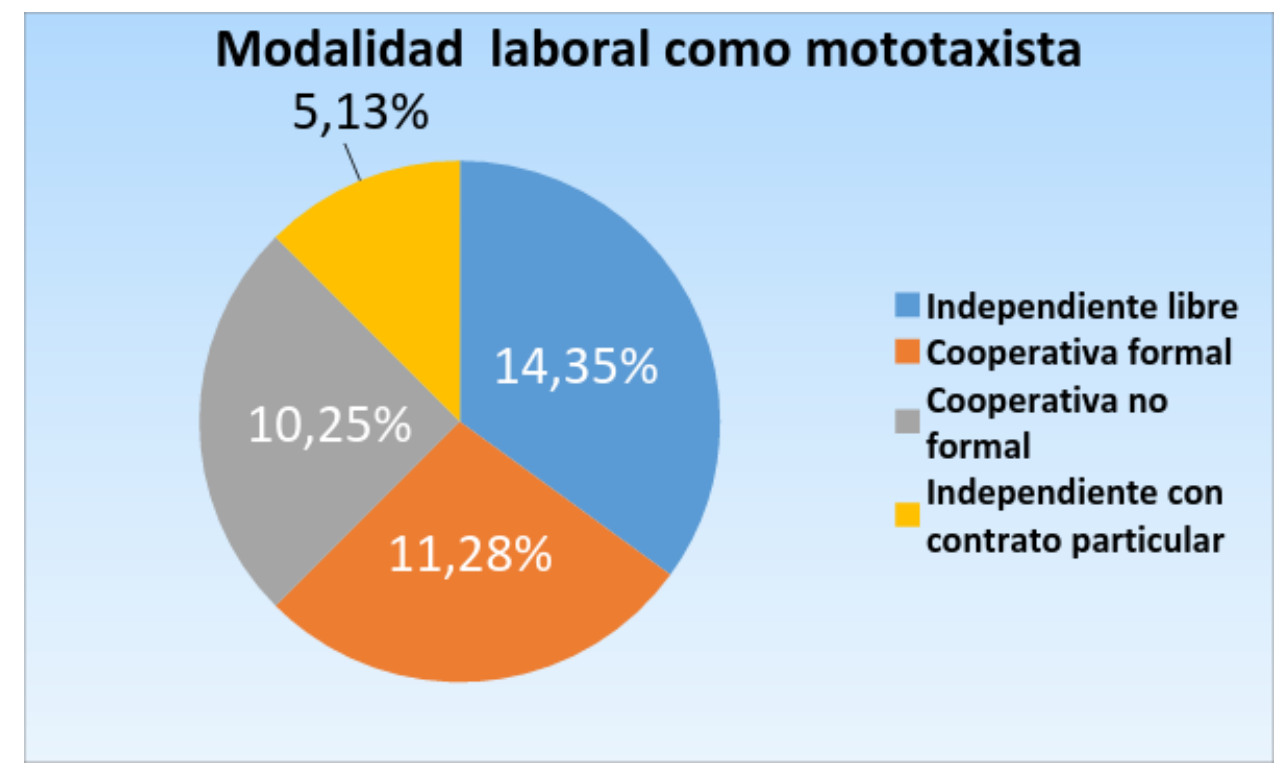

No existe una brecha significativa en los porcentajes de la modalidad laboral a la que se encuentran inscritos, aunque el usuario siente mayor seguridad y confiabilidad con los mototaxistas que se encuentran afiliados a cualquier gremio formal.

\section{Entrevistas a diferentes actores inherentes al mototaxismo}

Se escogieron por su pertinencia, tres actores estrechamente ligados con la problemática, para evaluar su opiniones y considerandos de la misma, información recopilada por medio de entrevistas semiestructuradas.

\section{Primera Entrevista-Dr. Jonathan Correa Ortega (SubGerente Operativo-Transucol Ltda)}

Autor Monografía: Qué opinión le merece esta modalidad de transporte público?

Dr.Correa: Particularmente, estoy en desacuerdo en considerar el motorratonismo como una alternativa de transporte público, primero porque es una actividad ilegal, segundo porque es una competencia desleal con los demás oferentes, y tercero porque es operado por personas que no tienen las competencias para desarrollar esta labor, en forma óptima, entendiendo por óptima, que el conductor sea prudente, experimentado y culto. 
Autor monografía: Ellos (los mototaxistas) argumentan que es una forma de ganarse la vida, de obtener el sustento para sus familias, que opina ud de esa posición?

Dr.Correa: No recuerdo que personaje de la historia... decía que ...el fin no justifica los medios...Ellos no pueden salir con eso, para justificar estas actividades, la gente puede ganarse la vida en forma honesta, mire esta empresa, ud puede ver gente como yo, o como estos jóvenes que ud ve allí, aquí los sueldos no son representativos, pero trabajamos en forma honesta, los motorratones pueden buscar trabajo, como mensajeros, porque no lo hacen entonces?...esto es un negocio, y la gente saca excusar para ganársela fácilmente.

Autor monografía: Según su punto de vista, como se ha visto afectado su empresa, persona, profesión, u oficio con la presencia activa de esta práctica de transporte?

Dr Correa: Mire, esta empresa maneja transporte público, operada por buses, busetas, camperos y taxis, y a ellos se les paga por entregas, o sea lo que se hagan en el dia, de acuerdo a un estimado de usuarios en un marco de tiempo determinado, y desde que aparecieron estos tipos, las entregas cada vez son más difíciles de cumplir, sobre todo a nivel urbano, que es donde los motorratones operan.

Autor monografía: Que aspectos negativos o positivos si existen, puede mencionar sobre esta práctica de transporte público desde su operatividad en el municipio de Palmira?

Dr Correa: Con todo respeto le podría citar solo aspectos negativos:

- Competencia desleal

- Incremento de la delincuencia

- Cultura de informalidad

- Pandillaje

- Incremento de los niveles de accidentalidad

- Delincuencia

Autor monografía: De acuerdo a su conocimiento, y experiencia cuales creen sean las causas que dieron origen a este fenómeno?

Dr Correa: Pienso particularmente, que hay dos factores que influyeron notablemente; la falta de oferta laboral en Palmira, que ha conllevado a la gente a que se "rebusque la vida", y la cultura del palmirano, aquí hay gente que no tiene esa capacidad de sacrificio que se requiere para esforzarse, muchas personas prefieren la informalidad y la obtención de dinero en forma fácil.

Autor monografía: Finalmente, y agradeciendo su tiempo y opinión, que alternativas de solución propone ud para el manejo de este fenómeno socioeconómico?

Dr Correa: Que lo eliminen en forma radical, y si no se puede que lo formalicen, para que compitan con estrategias formalizadas. 
Segunda Entrevista-Dra Nancy Stella Delgado Belárcazar (Abogada-ExSecretaria de Movilidad y Transporte Periodo 2008-2011)

Autor Monografía: Qué opinión le merece esta modalidad de transporte público?

Dra. Nancy Stella: Realmente es un flagelo en la extensión del término, uno no logra imaginarse el impacto social, económico, político que ha tenido esta supuesta modalidad de transporte público en las ciudades donde se ha asentado este fenómeno, en mi periplo al frente de la Secretaría, tuvimos cualquier cantidad de dificultades con esta gente, además de los incrementos en los índices de accidentalidad por esta inusual e informal práctica.

Autor monografía: Ellos (los mototaxistas) argumentan que es una forma de ganarse la vida, de obtener el sustento para sus familias, que opina ud de esa posición?

Dra.Nancy Stella: Estos argumentos son decididamente absurdos, incluso se ha vuelto un común denominador entre la gente que delinque, so pretexto de justificar sus actividades ilegales.

Autor monografía: Según su punto de vista, como se ha visto afectado su empresa, persona, profesión, u oficio con la presencia activa de esta práctica de transporte?

Dra Nancy Stella: Desde mi investidura profesional le puedo manifestar que los casos de delitos penales se han disparado, acceso carnal violento, robos, asalto a mano armada, motines en la calles, demandas por ilegalidad en el transporte, etc. Desde mi perspectiva personal, hacinamiento en las vías, imprudencias, accidentes, hostigamiento por parte de ellos para que uno utilice sus servicios, etc.

Autor monografía: Que aspectos negativos o positivos si existen, puede mencionar sobre esta práctica de transporte público desde su operatividad en el municipio de Palmira?

Dra Nancy Stella: Desde mi perspectiva, solo contemplo aspectos negativos:

- Índices incrementados de delincuencia

- Inculturación

- Violencia social

- Proliferación del sicariato

- Incremento de denuncias

- Aumento del nivel de economía informal

- Maltrato a la mujer

Autor monografía: De acuerdo a su conocimiento, y experiencia cuales creen sean las causas que dieron origen a este fenómeno?

Dra Nancy Stella: Puntualmente puedo afirmar, que a la falta de educación ciudadana, una educación con valores no permite la aparición de esta clase de contingencias en la ciudad. 
Autor monografía: Finalmente, y agradeciendo su tiempo y opinión, que alternativas de solución propone ud para el manejo de este fenómeno socioeconómico?

Dra Nancy Stella: Que las autoridades locales cumplan cabalmente con la normatividad vigente para el control y manejo de este flagelo.

Tercera Entrevista- Maryori Vanegas (Comerciante Revistas por catálogo) Autor Monografía: Qué opinión le merece esta modalidad de transporte público?

Maryori Vanegas: Agradezco la oportunidad que ud me brinda para decir que a despecho de lo que diga mucha gente, esta modalidad de transporte es muy útil, y pues suple una gran necesidad muy grande, porque antes para uno desplazarse tenía que "coger hasta dos rutas de buses" para llegar a ciertos destinos. Yo tengo varios amigos y familiares que trabajan en esto, y puedo dar fe que este transporte es bueno por donde se le mire.

Autor monografía: Ellos (los mototaxistas) argumentan que es una forma de ganarse la vida, de obtener el sustento para sus familias, que opina ud de esa posición?

Maryori Vanegas: Claro, no le digo que conozco mucha gente camellando en esto, y a todos nos le va igual... pero las personas se ganan sus pesitos en forma honrada, porque es que no hay donde trabajar, es decir, el trabajo no abunda...y ellos se rebuscan, estoy de acuerdo con su aporte es valioso, por ejemplo tengo dos primos, uno en Maria Cano y otro en el Barrio Popular Modelo, y ambos sustentan sus familias con este negocio.

Autor monografía: Según su punto de vista, como se ha visto afectado su empresa, persona, profesión, u oficio con la presencia activa de esta práctica de transporte?

Maryori Vanegas: Pues la verdad uno escucha también cosas malas también de esta gente, pero personalmente a mí no me ha pasado nada, y en vez de afectarme, a mí me ha beneficiado mucho, pues yo comercializo productos de una empresa llamada Natura, y me desplazo por todo Palmira, ofreciendo y llevando productos.

Autor monografía: Que aspectos negativos o positivos si existen, puede mencionar sobre esta práctica de transporte público desde su operatividad en el municipio de Palmira?

Maryori Vanegas: Pues negativos, que habido robos, hechos aislados de violaciones, accidentes, o que le da piojos a la gente... a mi me causa risa eso...y aspectos positivos, pues el llegar a tiempo a los destinos, la facilidad de encontrar siempre el servicio, la puntualidad, etc.

Autor monografía: De acuerdo a su conocimiento, y experiencia cuales creen sean las causas que dieron origen a este fenómeno?

Maryori Vanegas: Pues que le digo, pienso que surgieron para ofrecer un servicio ágil y oportuno, pues no había un tipo de transporte así. 
Autor monografía: Finalmente, y agradeciendo su tiempo y opinión, que alternativas de solución propone ud para el manejo de este fenómeno socioeconómico?

Maryori Vanegas: Que los motorratones se agrupen y formen cooperativas para que no haya problema, ya muchos están afiliados, y pues ofrecen un excelente servicio.

\section{Testimonios (Palmira)}

\section{José Luís Andrade (Mototaxista del sur de la ciudad)}

Trabajo hace un año y cuatro meses en la oficina del barrio El Recreo. Más que escoger este oficio, fue la única salida que encontré al quedarme desempleado después de que la empresa de vigilancia privada para la que trabajaba recortara personal. Sin empleo y con responsabilidades que cumplir, un anuncio en una revista lo conectó con la empresa de mototaxis. Lo único que le exigía era la moto y tener los documentos al día: pase, impuestos y seguro obligatorio. No me garantizaba un sueldo fijo ni seguridad social, pero en ese momento necesitaba trabajar. "Al comienzo fue muy duro, trabajar en la calle todo el día, el sol. Yo antes era más blanquito". Además, eso de ser motorratón me causaba un poco de vergüenza. Ahora me siento contento. En un buen día de trabajo logra ganar más o menos 30000 pesos de los cuales 5000 son para la empresa, 500 un aporte para la naciente cooperativa de la que hace parte y lo restante es para mí. Descansando dos domingos al mes, me pongo un sueldo de al menos $\$ 650.000$ pesos mensuales con los que, aparte de mantener a mi familia, corro con los gastos que la moto origina. La cooperativa se está organizando y pretende lograr que los motorratones miembros tengan seguridad social y prestaciones. Por ahora, si sufrimos algún tipo de accidente la cooperativa nos colabora con un 20 o 30\% de los gastos de la moto y si hay heridos hacen uso del seguro obligatorio.

Sin embargo, lo más duro para mi aparte del sol, son los taxistas que en muchas ocasiones, según él, le han "tirado el carro encima" y los guardas, que los persiguen así no estén transportando gente y les inmovilizan la moto.

\section{John Freyman Guevara, habitante del barrio Colombia, empleado público.}

Es muy grande el abuso de autoridad que viene teniendo la Policía Nacional con los mototaxistas y no sólo con ellos, sino con todas las personas que tiene su respectiva motocicleta para trasladarse.

Es impresionante cuando los agentes de policía montan un retén y persiguen las personas y se le abalanzan sobre sus vehículos y les quitan las llaves y el trato que se le está dando a las personas; se les está dando trato de animales o delincuentes, como si fueran los más peligrosos delincuentes de este país y no es así.

Sería bueno que hubiera una organización que le observara con atención esta situación que se está presentando en el municipio de Palmira.

\section{Libardo Martínez, abogado}


No hay ninguna parte de la Constitución que prohíba el derecho al trabajo, no estamos pretendiendo que se atente contra la seguridad Estatal. La gente está aburrida de que la estén humillando; usted protesta y de una vez le meten dos o tres partes y con esos pierde su moto; en cada parte se quiere quitar un salario mínimo.

Es un negocio redondo entre la Secretaria de Transito, el servicio de grúa y el parqueadero. La pelea debe ser legal, ellos hicieron un decreto que hay que tratar de tumbar, desbaratar ese decreto, después de que se suspenda ese decreto, la Secretaria de Transito no puede hacer nada.

Aunque no hago parte de los mototaxistas, no estoy de acuerdo que se agreda a la gente; que la Fuerza Pública la lesione.

\section{Leidy Johana Díaz, estudiante}

Yo estaba en el centro de la ciudad por ahí por la 29 con 28 esquina y decidí tomar un motorratón para que me llevará a la Benedicta; cuando veníamos, el conductor no pudo evitar el retén y un policía nos paró y le preguntó que si él era mototaxi; él dijo que no, que él no era motorratón; el policía le pregunto que quien era yo, el dijo que yo era la novia; no le creo, le dijo; cómo se llama ella. El conductor le respondió: ella se llama Leidy. Y a mí me preguntó: y él, cómo se llama. Yo le dije: Robinson.

El policía pregunto qué cuanto llevábamos de novios. Él dijo: apenas un mes. El policía le dijo al muchacho. Entonces, dele un beso para creerle, o si no, me deja su moto aquí y se va. Fue algo muy incómodo... pero me tocó hacerlo pa'que nos dejaran seguir...

\section{Compendio de opiniones de la gente}

"Las motos son un problema para esta ciudad pues ocasionan muchos accidentes y nadie nos da solución, que los quiten..." Luz Dary Pérez.

"Desde que se instauraron esos motorratones se nos ha dañado nuestro trabajo, ellos son más rápidos y nos quitan nuestras carreras" Grupo de taxistas.

"Los motorratones me han dado la mano, uno llega más temprano al trabajo y sale más barato" Marisol Izquierdo.

"Este trabajo es muy bueno gano fácil y no me jodo tanto" Motorratón.

"Si no fuera por este empleo mis hijitos y mi mujer estarían aguantando hambre, pues gracias a Dios me hago la platica diaria" Edwin Marmolejo.

\section{Resultados y discusión}

El tema del mototaxismo, es una problemática no solo interdisciplinaria sino pluriforme y compleja, porque conlleva dos perspectivas, el que la ve como un negocio porque toma esta práctica como una fuente de sustento; $y$ la otra perspectiva, que es la oferta de un servicio informal, anti técnico, ilegal por incumple los cánones tributarios, riesgoso, porque incumple las normas básicas de tránsito y seguridad. Dicha dicotomía transfiere lo económico, lo social y cultural. 
En Palmira, (ciudad sujeto de estudio), las opiniones están encontradas, y con base en esta investigación, es difícil establecer un panorama promisorio, puesto que hay muchos intereses encontrados.

\section{Conclusiones}

En Palmira, la situación se "salió de curso", y más de 4,000 personas sustentan sus hogares, mediante ejercicio de esta actividad, así que lo mejor es convivir con esta realidad.

Según los testimonios, las opiniones de las esquinas antagónicas entre los simpatizantes y detractores es fácil evidenciar que es más fácil aceptar esta modalidad de transporte que luchar por erradicarla.

La cultura e idiosincrasia de la municipalidad Palmira, aunado a la escasez de una oferta laboral suficiente, confluyeron para que esta práctica tuviera tanto impacto en la ciudad.

El mototaxismo es un fenómeno, que por su incidencia y poder mediático en la sociedad, es imposible de detener, por ende, se deben crear mecanismos de control y manejo, más que de erradicación.

\section{Literatura citada}

Ardila, A. (2006). El Mototaxismo: causas y posibles soluciones. Recuperado de http:// http://www.voltairenet.org/article143679.html. Red Voltaire.

Brieva Paternina, J. (2010). El mototaxismo en Sincelejo: Un análisis socioeconómico. Recuperado de http:// http://www.pnud.org.co/img_upload/9056f18133669868e1cc381983d50faa/prime rapagina.pdf.

López, C. d. (2011). Pobreza, desempleo y exclusión, génesis del mototaxismo. UN Medios.

Raya Bayona, L. (2010). Mototaxis: el nuevo transporte público. Recuperado de http:// http://www.consumer.es/web/es/motor/educacion_y_seguridad_vial/2010/11/04/1 96876.php.

Saénz, N. (2011). Politica y sociedad: Mototaxismo en Colombia. UN Medios. 